\title{
Correction to: Occupational exposure to organic solvents and breast cancer risk: a systematic review and meta-analysis
}

\author{
Wenxuan Xiao ${ }^{1}$. Jinglong Huang ${ }^{1} \cdot$ Jianing Wang ${ }^{2} \cdot$ Youli Chen $^{1} \cdot \mathrm{Nan} \mathrm{Hu}^{3} \cdot$ Shiyi Cao $^{2}$
}

Published online: 20 November 2021

๑) Springer-Verlag GmbH Germany, part of Springer Nature 2021

Correction to: Environmental Science and Pollution Research https://doi.org/10.1007/s11356-021-17100-6

The statement for the equal contribution of the Authors is inserted in the proof.

The Original article has been corrected.

Publisher's Note Springer Nature remains neutral with regard to jurisdictional claims in published maps and institutional affiliations.

The original article can be found online at https://doi.org/10.1007/ s11356-021-17100-6.

\section{Shiyi Cao}

caoshiyi@hust.edu.cn

1 Union Hospital, Tongji Medical College, Huazhong

University of Science and Technology, Wuhan 430022,

China

2 School of Public Health, Tongji Medical College, Huazhong University of Science and Technology, Wuhan 430030,

China

3 Department of Neurology, Peking Union Medical College Hospital, Beijing 100730, China 